\title{
Gestalt psychotherapy in the outpatient treatment of borderline personality disorder: a case report
}

Borderline personality disorder (BPD) is the most frequent and the most severe of all personality disorders in clinical practice. Although BPD bears the reputation of being "untreatable", psychotherapy for patients with BPD has been the treatment of choice. ${ }^{1,2}$ A number of papers show the use and effectiveness of various psychotherapeutic approaches. ${ }^{3-10}$ This article presents the use of Gestalt psychotherapy in the treatment of BPD patients. The authors obtained the informed consent of the client for publication of this content.

A 30 year old female sought therapy for the following reasons (in her own words): She experienced a sensation of walking on the border between life and death, and a feeling of emptiness and being unwell. Nothing made sense for her, she was sad and dissatisfied with all aspects of her life, and it seemed that nothing was good enough.

She had been unable to establish an intimate relationship for the last seven years. Her family of origin was complete but she described a chaotic family life, characterised by regular physical and psychological abuse despite the maintenance of a normal facade.

During initial diagnostic evaluation, the psychological tests showed difficulties in social communication and adjustment, as well as hypersensitivity, feelings of deprivation and adoption of the victim role, accompanied by difficulties in close emotional relations. Inhibitory capacities were reduced, maladaptive irritability was prominent, the behavior was unpredictable, impulsive, not constructive, and the risk of aggressive responses was present in addition to the elements of borderline personality structure. General defence activity was low. The predominantly used defence mechanism was intellectualization and affect was suppressed. Projective tests showed that early family relationships represented an important area of conflict. Although the deficit of basic trust and safety was clearly visible, the effort to idealize herself and other people was present.

On initial psychiatric interview, frequent changes of mood were noted in keeping with the personality structure, fragmented psychotic reactions as well as self-destructive behaviour could also be experienced. Consequently, a diagnosis of BPD was made.

The Gestalt psychotherapy was carried out through 75 individual sessions. The emphasis of this individual work was placed on building the client-therapist relationship; developing the patient's sense of their own value, instituting personal boundaries and limitations; developing productive verbal expression and on the establishment of continuity of the therapy.

Correspondence

DrR Knez

email: rajna@hi.htnet.hr
The therapy was carried out through dialogues and exercises during individual sessions: creation of a genogram, collages and drawings; therapy with associative cards and through The Diary of Awareness that the patient kept throughout the last year of therapy.

Initially, it was very hard to establish continuity of attendance at therapy; hence the 75 sessions were unevenly spaced over three and a half years. In the beginning, the patient displayed a significant need to control the relationship. When she felt the relationship was not developing "as it should have", she was either retreating or attacking towards the process. This pattern of behaviour was mirrored by numerous problems in her social relationships.

During psychotherapy, special emphasis was given to her developing awareness of her feelings and to timely recognition of her feelings that could allow conscious selection of responses towards others.

At the beginning of the therapy the patient was able to establish relationships with ease, but those relationships remained shallow and cold due to her difficulties in allowing herself to become involved in deep and sincere relations. Strengthening and increasing capacity for self-acceptance created the prerequisites for the patient to become more open towards others and to stand up for herself.

The patient tried to cope with her emotional difficulties by rationalization and involvement in a series of professional tasks. Through the therapy she learned not to get involved in new activities before allowing herself to recognize how she felt about them. She also learned not to constantly act out her impulses, but to seek alternative perspectives and to foresee the consequences of her actions.

More often than not she blamed others for her failures and had great difficulty accepting personal responsibility. However, therapeutic work directed towards tolerating personal responsibilities helped to diminish her sense of being treated badly by the people in her environment.

During the last year of therapy, the patient was able to maintain continuity, mostly on a weekly basis. She also graduated from University after twelve years of attendance, entered a higher level graduate program, moved out of her parents' home and bought her own apartment, established a deep emotional relationship with a male partner leading to marriage, kept her permanent job in a government firm, and started her own business.

The results of follow-up psychological testing showed improved functioning, significantly reduced problems of social adjustment and communication, as well as a tendency of engagement in close personal relationships and increased levels of trust. The feelings of deprivation and the role of 
victim that were pronounced in the first psychological testing diminished. The personality structure remained a prominent feature, but she developed better control, realistic insight and higher levels of social regulation. She anticipated a positive future; she stated satisfaction with the changes she had achieved, with herself, and her current life circumstances.

The therapist's impressions were that the patient had significantly increased her capacity for self-regulation of emotions, accepted responsibility for her choices in life, significantly stabilized her sense of self and improved the integration of the fragmented pieces of her personality.

Through this case report, we demonstrate how change achieved during Gestalt psychotherapy reveals not just a reduction of symptoms of the disease, but also the impact it has on fundamental aspects of personality functioning evidenced by success in developing and maintaining an intimate relationship and friendships and achieving a greater ability to function educationally, occupationally and socially.

R Knez, L Gudelj, H Sveško-Visentin University Hospital Center Rijeka, Department of Psychiatry, Rijeka, Croatia

\section{References}

1. Chanen AM, MCCutcheon LK, Jovev M, Jackson HJ, MCGorry PD. Prevention and early intervention for borderline personality disorder. Med J Aust 2007;187:S18-S21.

2. Sadock BJ, Sadock VA. Kaplan\&Sadock's synopsis of psychiatry: Behavioral sciences/clinical psychiatry. Lippincott Williams \&
Wilkins. 10th ed. Philadelphia 2007;799.

3. Binks CA, Fenton M, MCCarthy L et al. Psychological therapies for people with borderline personality disorder. Cochrane Database of Syst Rev 2006; 1:CD005652.

4. Giesen-Bloo J, Van Dyck R, Spinhoven P et al. Outpatient psychotherapy for borderline personality disorder: randomized trial of schema-focused therapy vs transference-focused psychotherapy. Arch Gen Psychiatry 2006;63(6):649-58.

5. Clarkin JF, Levy KN, Lenzenweger MF, Kernberg OF. Evaluating three treatments for borderline personality disorder: a multiwave study. Am J Psychiatry 2007; 164(6):922-8.

6. Leichsenring F, Masuhr O, Jaeger $U$ et al. The effectiveness of psychoanalytic-interactional therapy in borderline personality disorder: a study of clinical data. Psychosom Med Psychoth 2007;53(2):129-43.

7. Davidson K, Norrie J, Tyrer P, Gunley A, Tata P, Murray M et al. The effectiveness of cognitive behavior therapy for borderline personality disorder: results from the borderline personality disorder study of cognitive therapy (BOSCOT) trial. J Pers Disord 2006;20(5):450-65.

8. Farrell JM, Shaw IA, Webber MA. A schema-focused approach to group psychotherapy for outpatients with borderline personality disorder: A randomized controlled trial. J Behav Ther Exp Psychiatry 2009;40(2):317-28.

9. Zanarini MC. Psychotherapy of borderline personality disorder. Acta Psychiatr Scand 2009;120(5):373-7.

10. Stone MH. Management of borderline personality disorder: a review of psychotherapeutic approaches. World Psychiatry 2006;5(1):15

\section{Dementia masquerading as mania - when should it be suspected?}

Frontotemporal Dementia (FTD) is a degenerative disorder of the brain that affects the frontal and temporal cortices resulting in impairments in reasoning, personality, movement, speech, social graces, language and memory. The changes in personal and social conduct, which occur in the early stages of the disease, include loss of inhibition, apathy, social withdrawal, hyperorality and ritualistic compulsive behaviors. These changes can be dramatic and may be misdiagnosed as a psychiatric disorder. ${ }^{1}$ We present a case wherein FTD was misdiagnosed and treated as mania and highlight the features of late-onset 'mania' that should raise clinical suspicion.

The patient's family consented to the reporting of this case. Mr. M, a 56 year old man with 10 years of formal education, working as an agriculturist was brought to our centre by his family who were greatly distressed by changes in his behaviour

\section{Correspondence}

DrR Shah

email: druchitashah@gmail.com and personality. These alterations developed gradually over 2 years. There was no past or family history of any affective or psychotic illness. He was oblivious to any inappropriateness in his behavior, however, complained of 'tension'. Initially the family noticed irritability followed by other changes - spending excessive time on the phone, taking extra measures for grooming and watching music and fashion television programs excessively. Also, he started talking of business plans that the sons thought of as preposterous and foolish. His facial expression was usually stiff with no play of emotions but, occasionally, he would suddenly weep. There was a decrease in sleep and increased demand and intake of specific food items (fruit juices and milk). In addition, he started demanding sexual activity more often from his wife and was frequently found staring at women in the neighbourhood. Also, he recommenced drinking alcohol and smoking after quitting for several years.

Mr. M was diagnosed with mania by private psychiatrists and prescribed antipsychotic drugs. When first seen at our centre, a diagnosis of mania versus psychosis was made and he was prescribed paliperidone and sodium valproate. However, a 